\title{
Airway epithelium expresses interleukin-18
}

\author{
L.A. Cameron*, R.A. Taha*, A. Tsicopoulos", M. Kurimoto*, R. Olivenstein*, B. Wallaert", \\ E.M. Minshall*, Q.A. Hamid*
}

Airway epithelium expresses interleukin-18. L.A. Cameron, R.A. Taha, A. Tsicopoulos, M. Kurimoto, R. Olivenstein, B. Wallaert, E.M. Minshall, Q.A. Hamid. (C)ERS Journals Ltd 1999.

ABSTRACT: Interleukin(IL)-18 is an interferon (IFN)- $\gamma$-inducing cytokine suggested to be important in regulating inflammatory responses. This study investigated the pulmonary expression of IL-18 under conditions characterized by T-helper (Th)1 (lipopolysaccharide (LPS) treatment/sarcoidosis) and Th2 (ovalbumin (OVA) challenge/asthma) cytokine production.

In situ hybridization and immunocytochemistry were used to determine the number of cells expressing IL-18, IFN- $\gamma$, IL-5 and major basic protein (MBP) within lung tissue from Balb/c mice stimulated with LPS, OVA and in normal control mice. Bronchial biopsies from patients with sarcoidosis, asthma and control individuals were also examined.

IL-18 was localized primarily to airway epithelium and mononuclear cells. Constitutive expression was observed within the lungs of control mice. Animals challenged with LPS exhibited more IL-18 messenger ribonucleic acid (mRNA)-positive and IFN$\gamma$ immunoreactive cells, compared to control mice $(\mathbf{p}<0.01)$. OVA-challenged mice had fewer IL-18 mRNA positive and more IL-5 and MBP immunoreactive cells, compared to control mice $(p<0.01)$. Similarly, constitutive expression of IL-18 protein was observed within the airway epithelium of control individuals, with more positive cells found within sarcoidosis tissue $(p<0.01)$ and fewer within asthmatic tissue $(p<0.01)$, compared to controls.

These results demonstrate the expression of interleukin-18 within airway epithelium and the regulation of this cytokine under conditions of both T-helper1 and Thelper2 cytokine production.

Eur Respir J 1999; 14: 553-559.
*Meakins-Christie Laboratories and Montreal Chest Institute Research Center, McGill University, Montreal, Quebec, Canada, ${ }^{\#}$ Pathologie Immuno-allergique Respiratoire et Cellules Inflammatoires, INSERM U416, Institut Pasteur de Lille,

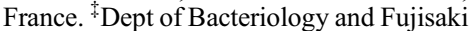
Institute, Hayashibara Biochemical Laboratories, Hayashibara Co. Inc., Okayama, Japan.

Correspondence: Q.A. Hamid, MeakinsChristie Laboratories, 3626 St. Urbain St. Montreal, PQ H2X 2P2. Fax: 514 3987483

\section{Keywords: Airway epithelium interleukin-18}

T-helper 1 disease

Received: November 41998

Accepted after revision April 171999

Supported by MRCCanada, Inspiraplex, the J.T. Costello Memorial Research Foundation and Ministere de la Sante (PHRC 1994). Q.A. Hamid is the recipient of a Chercheur-Boursier award from the Fonds de la Recherche en Sante du Quebec.
Interleukin (IL)-18 is an $18.3 \mathrm{kDa}$ protein first identified in murine Kupffer cells following treatment with Propionibacterium acnes and lipopolysaccharide (LPS) challenge [1]. Initially, IL-18 was termed interferon (IFN)- $\gamma$-inducing factor (IGIF) by OKAMURA et al. [1] due to its ability to induce IFN- $\gamma$ production in established T-helper (Th) 1 clones. In this system, IL-12 and IL-18 were shown to act on the T-cells in an independent but synergistic fashion [1]. While there is controversy regarding whether IL-18 can act independently of IL-12 [2-5], BARBULESCU et al. [6] have demonstrated that in peripheral blood CD4 T-cells, IL-18 acts directly on the IFN- $\gamma$ promoter to induce high cytokine expression.

In addition to T-cells, IL-18 can induce IFN- $\gamma$ production in natural killer (NK) cells, enhancing their cytotoxic activity [7], $\mathrm{B}$ cells, initiating immunoglobulin (Ig)G2a production and suppression of IgE [2] and bone marrow derived macrophages, providing autocrine activation of these cells [3]. Despite the fact that IL-18 is recognized as a pleiotrophic cytokine, it is unclear whether its mechanism of action is similar for all cell types. IL-18 has also been shown to promote the production of other cytokines (granulocyte-macrophage colony-stimulating factor (GM-CSF), IL-2, IL- $\beta$ and IL-18 $[8,9]$ ), chemokines (monocyte chemotactic protein (MCP)-1 and macrophage inflammatory protein (MIP)-1 $\alpha$ [9]), and to inhibit the production of IL-10 [8]. However, recent reports failed to demonstrate this inhibition [9, 10]. As such, it seems that IL-18 may play a prominent role in the regulation of immune responses in an autocrine, paracrine and even chemotactic manner.

Studies on liver [1, 11], pancreatic tissue [12] and skin [13] have localized IL-18 mainly to activated macrophages and keratinocytes. In addition, TAKEUCHI et al. [14] have demonstrated high expression of IL-18 in intestinal mucosal epithelial cells. To date, however, no studies have investigated the cellular expression of IL-18 within the airways. In this study, in situ hybridization and immunocytochemistry were used to examine IL-18 expression within lung tissue from $\mathrm{Balb} / \mathrm{c}$ mice following challenge with agents that induce Th1 and Th2 cytokine production (LPS [15] and ovalbumin (OVA) [16], respectively). As a clinical correlate, bronchial biopsies from patients with the Th1 and Th2 mediated diseases, sarcoidosis and asthma, respectively were also examined. Immunocytochemistry was employed to determine the expression of IFN- $\gamma$, IL- 5 and the presence of eosinophils.

\section{Materials and methods}

Animals

Male Balb/c mice (6-8 weeks old) were obtained from a commercial supplier (Jackson Laboratories, Bar Harbor, 
ME, USA) and housed in a conventional animal facility at the authors' laboratory. Six animals were challenged with LPS (Sigma Chemical Co., St. Louis, MO, USA) and six sensitized and studied 14 days later following acute challenge with OVA (Sigma Chemical Co.). Normal nonchallenged mice were used as controls. All methods used in these experiments were evaluated and approved by the Animal Ethics committee at McGill University.

\section{Study design}

Lipopolysaccharide challenge. Six Balb/c mice were challenged with $10 \mu \mathrm{g}$ of LPS by intraperitoneal injection, as previously described [17]. LPS administration has been shown to induce the expression of the Th1 cytokines IL-12 and IFN- $\gamma$ [15] and other pro-inflammatory changes within the lung [17].

Antigen sensitization and challenge. Six Balb/c mice were sensitized and challenged with OVA according to a protocol modified from that previously shown to induce late airway responses and airway inflammation in rats [18]. Briefly, $100 \mu \mathrm{g}$ OVA and $0.43 \mathrm{mg}$ aluminium hydroxide gel (BHD Chemicals, Poole, UK) were dissolved in $0.5 \mathrm{~mL}$ of saline and injected subcutaneously, while $0.5 \mathrm{~mL}$ Bordetella Pertussis vaccine (IAF BioVac, Laval, Quebec, Canada) with $2 \times 10^{9}$ heat-killed organisms was injected intraperitoneally as an adjuvant. Fourteen days after sensitization, intratracheal challenge with OVA was performed. The mice were sedated with xylazine $\left(8 \mathrm{mg} \cdot \mathrm{kg}^{-1}\right.$ i.p. $)$, anaesthetized with sodium pentobarbital $\left(70 \mathrm{mg} \cdot \mathrm{kg}^{-1}\right.$ i.p. $)$ and then restrained on a board at a fixed angle. Mice then received OVA (100 $\mu \mathrm{g} ; 50 \mu \mathrm{L}$ ) by intratracheal instillation using a bluntended $21 \mathrm{G}$ needle. The mice were then allowed to recover from the anaesthesia.

Lung dissection and processing. Six hours following OVA and $24 \mathrm{~h}$ following LPS challenge, time points associated with optimal changes in cytokine expression $[16,17]$, the lungs were obtained. Both LPS- and OVA-treated mice were anaesthetized with a lethal dose of sodium pentobarbital $\left(60 \mathrm{mg} \cdot \mathrm{kg}^{-1}\right)$. The animals were intubated by tracheotomy with a blunt-ended $21 \mathrm{G}$ syringe, the lungs filled with $1 \mathrm{~mL}$ of $4 \%$ paraformaldehyde, so as to be fixed in an inflated state. The anterior chest wall was removed and mice were exsanguinated by vena cava section. The heart and lungs were excised together, to ensure that the lungs were not damaged in the process, and then placed in $4 \%$ paraformaldehyde for a period of 2 $\mathrm{h}$ and then washed in $15 \%$ sucrose/phosphate buffered saline (PBS) three times ( $1 \mathrm{~h}$ each). Following this, tissue was blocked in optimal cutting temperature (OCT) medium (Miles Inc., Elkhart, IN, USA) and snap frozen in liquid nitrogen-cooled isopentane. Blocks were stored at $-80^{\circ} \mathrm{C}$ until required.

\section{Subjects}

Six patients with active sarcoidosis, six asthmatics and six normal control subjects were entered into the study. Ethical approval for the study was obtained from the Calmette Hospital Ethics Committee and the Montreal Chest Institute, respectively. Written informed consent was obtained from all patients and subjects before the bronchoscopy.
Sarcoidosis. The sarcoidosis patients (five females and one male), with a mean age of 47 yrs (range 31-65), were newly diagnosed with active disease. All patients were nonsmokers, had no history of allergy, exhibited a negative skin prick test to common aeroallergens and had not received any corticosteroid treatment in the last year. Pulmonary sarcoidosis was diagnosed on the basis of previously described criteria [19] which included lung or mediastinal lymph node biopsy demonstrating evidence of noncaseating epithelioid cell granulomas. All patients had a confirmed histological diagnosis of sarcoidosis and radiographical staging indicated that four patients had stage II and two patients had stage I disease. Active sarcoidosis was assessed by a number of criteria: 1) the recent development or increase of cough or dyspnoea; and/or 2) systemic symptoms such as cutaneous lesions, weakness, fever, arthralgia; and/or 3 ) increasing opacities on chest radiograph. Patients did not exhibit any airflow limitation as measured by per cent predicted forced expiratory volume in one second (FEV1), with a mean of $101.7 \%$ pred (range $77-122$ ) or pulmonary restriction. The patients were recruited through the Department of Pneumoimmunoallergy, Calmette Hospital, Lille, France.

Asthmatics. Asthma was diagnosed according to the American Thoracic Society criteria [20]. All patients (three females, three males), with a mean age of $38 \mathrm{yrs}$ (range 19-60), were nonsmokers and had not received inhaled or oral steroid therapy in the 3 months prior to recruitment. Asthmatic subjects (three atopic, three nonatopic) were studied in a stable condition and had clinically mild asthma with a baseline FEV1 $>70 \%$ pred (range $74-128$ ). All asthmatic subjects had an increased bronchial reactivity to inhaled methacholine as measured by the provocative dose of methacholine causing a $20 \%$ fall in FEV1 (PC20) of $<8 \mathrm{mg} \cdot \mathrm{mL}^{-1}$.

Control subjects. Control subjects (two females, four males), with mean age of 34 yrs (range 23-54), recruited for this study had no history of asthma or allergy, were nonsmokers and were free of any other pulmonary disease. $\mathrm{PC}_{20}$ values for these patients were all $>16 \mathrm{mg}$. $\mathrm{mL}^{-1}$.

Bronchoscopy. Bronchial biopsies were obtained from the patients with sarcoidosis and asthma, and normal control subjects by fibreoptic bronchoscopy performed following the American Thoracic Society guidelines [21]. Patients were given an intravenous injection of midazolam (1-5 mg) and a metered dose inhalation of albuterol $(400 \mu \mathrm{g})$. A $4 \%$ lidocaine solution was used for topical anaesthesia, continuous oxymetry was performed and oxygen was given throughout the procedure. Six to eight biopsies were obtained from the segmental divisions at the right lower and middle lobe using alligator forceps (Olympus Corp., Tokyo, Japan). Bronchial biopsies were blocked immediately by embedding the tissue in OCT medium and snap freezing it in liquid nitrogen-cooled isopentane. Blocks were stored at $-80^{\circ} \mathrm{C}$ until use.

Immunocytochemistry. Cryostat sections were prepared from blocks of both human and murine lung tissue. Cytokine expression was assessed using the alkaline 
phosphatase anti-alkaline phosphatase (APAAP) staining method [22] with biotinylated goat anti-mouse IFN- $\gamma$ (DAKO Canada Inc., Missisauga, Ontario, Canada) and rat anti-mouse monoclonal IL-5 antibodies (TRFK-5; Schering-Plough Research Institute, NJ, USA). The presence of eosinophils was determined using a rabbit anti-mouse antibody against major basic protein (MBP; a kind gift from G. Gleich, Mayo Clinic, Rochester, MN, USA). The reaction was visualized using fast red TR (Sigma Chemical Co.). Mouse anti-human monoclonal antibody was employed to detect IL-18 immunoreactivity in human lung sections (R\&D Systems Inc., Minneapolis, MN, USA) with the avidin-biotin complex $(\mathrm{ABC})$ method and diaminobenzidine for visualization [23]. All sections were counterstained with haematoxylin. Negative control experiments were performed in a similar manner but in the absence of the primary antibody.

In situ hybridization. In situ hybridization was employed to examine the expression of mouse IL-18 messenger ribonucleic acid (mRNA) as seen previously [24]. Probes complementary to IL-18 mRNA were prepared from complementary deoxyribonucleic acid (cDNA) cloned in a pMuGF37B-5 vector (Stratagene La Jolla, CA, USA) and linearized with the restriction enzymes Kpn1 for anti-sense (complementary) and Sac-1 for sense (identical) probes. In the presence of ${ }^{35} \mathrm{~S}$-uridine triphosphate (UTP), the RNA probes were generated by in vitro transcription using the polymerase enzymes $\mathrm{T} 7$ and T3. Cryostat sections of lung tissue were permeabilized with $0.1 \mu \mathrm{g} \cdot \mathrm{mL}^{-1}$ proteinase $\mathrm{K}$ and then prehybridized with $50 \%$ formamide and $2 \times$ standard saline citrate. Following application of the radiolabelled probe $\left(0.75 \times 10^{6} \mathrm{cpm}\right.$. section $)$, the sections were hybridized at $42^{\circ} \mathrm{C}$ overnight. High stringency post-hybridization washes, using decreasing concentrations of standard saline nitrate $(\mathrm{SSC})$ solution $(4 \times-0.1 \times \mathrm{SSC})$ at a relatively high temperature of $42^{\circ} \mathrm{C}$, were used to reduce nonspecific binding and excess probe was destroyed by treating the slides with an Rnase A solution $\left(20 \mu \mathrm{g} \cdot \mathrm{mL}^{-1}\right)$. The hybridization signal was visualized by incubating the sections overnight with Amersham LM-2 emulsion (Amersham, Oakville, Ontario, Canada), storing them at $4^{\circ} \mathrm{C}$ for a period of 12-14 days, development in Kodak D-19 solution (Eastmean kodak, Torronto, Canada) and counterstaining with haematoxylin. Slides were examined using light microscopy and a positive signal was identified as a collection of dense silver grains overlying the cells. Negative control experiments using sense probes and RNase pretreatment of sections prior to antisense probe application were performed to confirm probe specificity.

Quantification and statistical analysis. Slides were coded and read blindly using an Olympus light microscope (Carson Group Inc., Markam, Ontario, Canada) at $200 \times$ magnification. The graticule was placed under the basement membrane, the number of positive cells were counted and reported as the mean of at least $6-8$ grids and expressed as number of positive cells per square millimetre of membrane. Epithelial staining was quantified as a per cent positive staining of the total epithelium. Data were expressed as mean \pm SD and analysed using either the Kolmogorov-Smirnov two sample test or analysis of variance (ANOVA) (SyStat version 7.0; SyStat Inc. Evanston, IL, USA); $<<0.05$ was considered significant.

\section{Results}

Murine expression of interleukin-18 messenger ribonucleic acid

Specific IL-18 mRNA signals were detected in all animals. While the majority of the signal was localized to airway epithelium, mainly cuboidal in phenotype, the inflammatory cells within the airway wall and parenchyma also expressed IL-18 mRNA (fig. 1). Histologically, these cells were mostly mononuclear, exhibiting features consistent with the lymphocyte. A number of granulocytes, mainly neutrophils, were also positive for IL-18 mRNA, particularly in the LPS-treated group. Figure 2 shows that the percentage of epithelial cells positive for IL-18 mRNA per square millimetre of basement membrane was significantly higher in the LPS treated animals $(57 \pm 9.1$; fig. 1a) compared to the control mice $(15.5 \pm 3.73$; $\mathrm{p}<$ $0.001)$ as well as OVA-challenged mice $(6.3 \pm 4.0 ; \mathrm{p}<$ 0.001 ; fig. 1b). Furthermore, there were significantly fewer IL-18 mRNA positive cells in OVA challenged animals compared to the control $(\mathrm{p}<0.05)$. The number of submucosal inflammatory cells expressing IL-18 mRNA per square millimetre of membrane is illustrated in figure 3. Similarly, more IL-18 mRNA positive cells were seen within the lungs of the LPS-treated mice $(50.5 \pm 9.1)$ compared to the control $(18.3 \pm 4.7 ; \mathrm{p}<0.001)$ and OVAchallenged mice $(8.0 \pm 3.9 ; \mathrm{p}<0.001)$. No specific mRNA was detected in the alveolar epithelium or airway smooth muscle.

\section{Interferon gamma, interleukin-5 and major basic protein immunoreactivity within the murine lung}

Figure 4 shows the mean number of IFN- $\gamma$, IL- 5 and MBP-immunoreactive cells in lung sections from LPStreated, OVA-challenged and control mice. Animals treated with LPS exhibited a higher number of IFN- $\gamma$ immunoreactive cells $(30.17 \pm 4.31)$ compared to the control group $(9.5 \pm 2.9 ; \mathrm{p}<0.001$, fig. $4 \mathrm{a})$. An increase in MBP (6.5 \pm 2.4$)$ and IL-5 (6.0 \pm 1.7$)$ immunoreactivity was also detected in LPS-treated animals, compared to control mice $(0.83 \pm 1.3$ versus $1.83 \pm 2.1 ; \mathrm{p}<0.05$, figs. $4 \mathrm{~b}$ and $\mathrm{c}$ ).

Ova-challenged mice were observed to have a large number (mainly around the airways) of cells expressing MBP (39.0 \pm 10.3$)$ and IL-5 (29.3 \pm 7.0$)$ immunoreactivity, significantly higher than the LPS-treated or control group $(\mathrm{p}<0.001$, figs. $4 \mathrm{a}$ and $\mathrm{b})$. Scattered IFN- $\gamma$-positive cells were also detected following OVA challenge, however, their number was substantially lower than LPS-treated and control mice (data not shown).

\section{Interleukin-18 immunoreactivity within the human airway epithelium}

Figure 5 illustrates the percentage of epithelium exhibiting IL-18 immunoreactivity within bronchial biopsies from control subjects and patients with either 

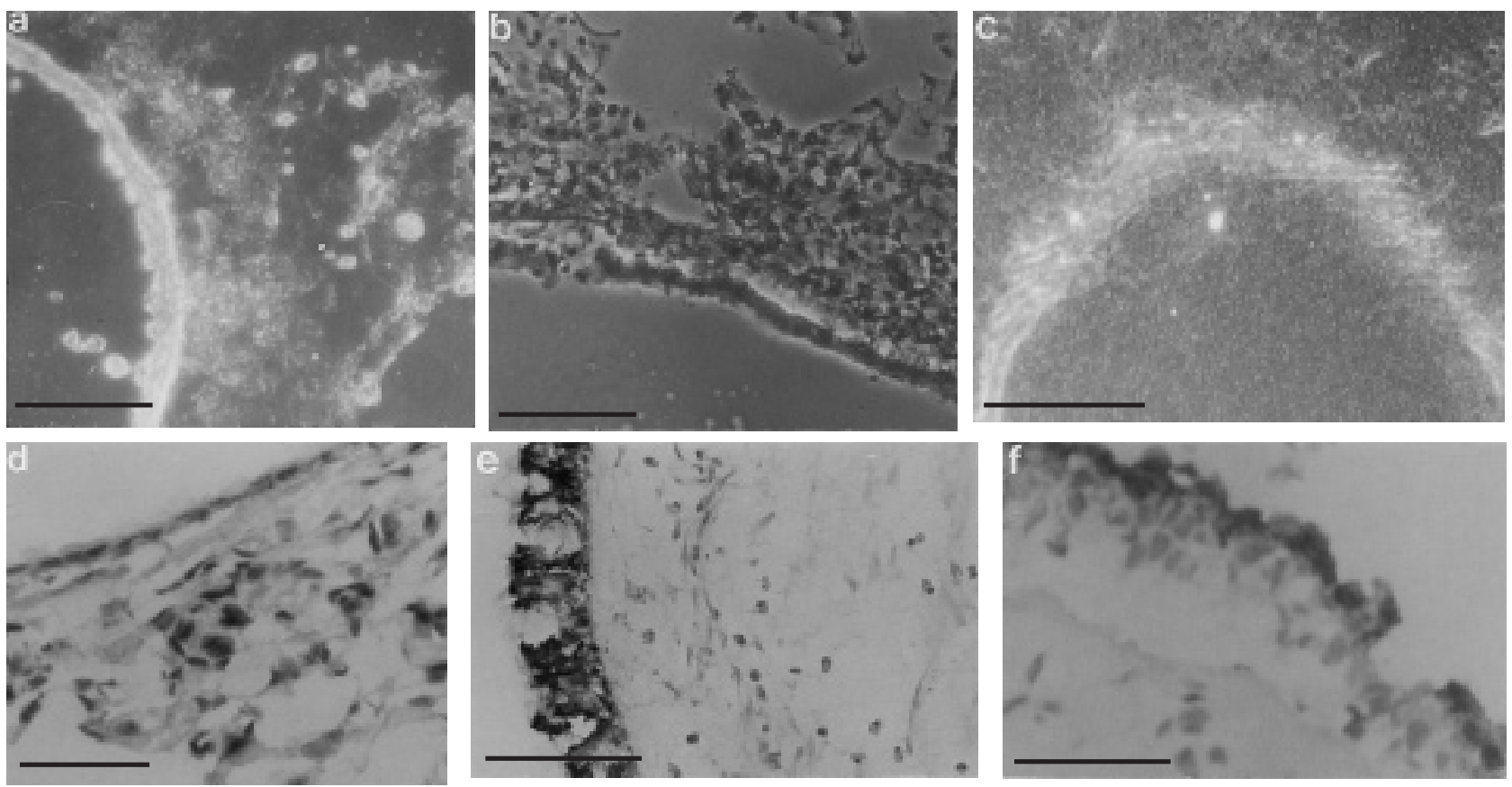

Fig. 1. - Representative photomicrographs of mouse lung tissue and human bronchial biopsies. There is a high expression of interleukin (IL)-18 messenger ribonucleic acid (mRNA) within the epithelium and submucosa of lipopolysaccharide (LPS)-treated mice (a), while ovalbumin (OVA) challenge was associated with a much lower expression (b) compared to the constitutive presence within control mice (c). Interferon (IFN)- $\gamma$ immunoreactivity can be seen within the submucosa of mouse lung tissue following treatment with LPS (d). Strong epithelial staining of IL-18 protein is observed within bronchial biopsies obtained from patients with sarcoidosis (e), while a less pronounced staining is seen within asthmatic patients (f). Internal scale bars $=100 \mu \mathrm{m}$.

sarcoidosis or asthma. Bronchial tissue from all three groups exhibited positive staining for IL-18, mainly within columnar epithelial cells. The percentage of epithelium demonstrating IL-18 immunoreactivity was significantly higher in patients with sarcoidosis $(75.0 \pm 13.8 ; \mathrm{p}<0.001)$ and significantly less within asthmatic tissue (5.8 \pm 5.8 ; $\mathrm{p}<0.001)$, compared to normal control subjects $(34.2 \pm$ 11.6).

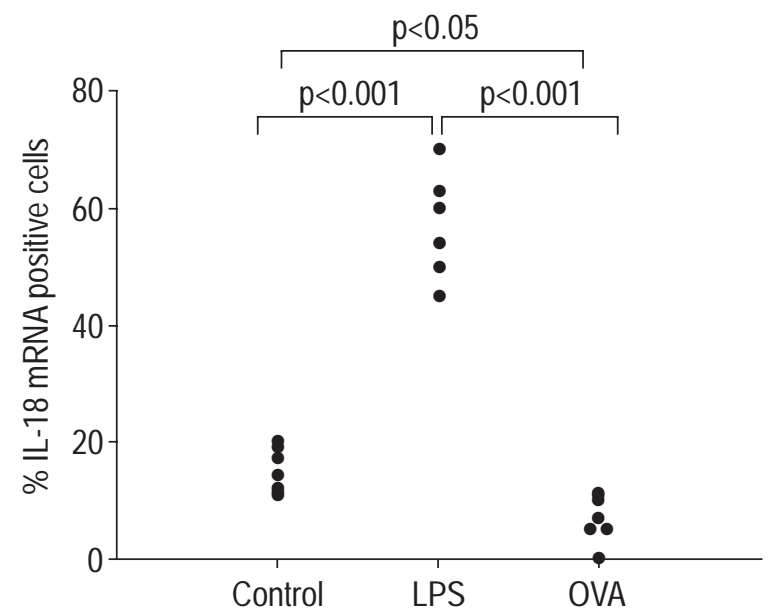

Fig. 2. - The percentage of epithelial cells positive for interleukin (IL)18 messenger ribonucleic acid (mRNA) per millimetre of basement membrane. The percentage of IL-18 mRNA positive cells was significantly higher within the lipopolysaccharide (LPS)-treated mice compared to the control $(\mathrm{p}<0.001)$ and ovalbumin $(\mathrm{OVA})$-challenged mice $(\mathrm{p}<0.001)$. The percentage of IL-18 mRNA positive cells within the OVA-challenged animals was significantly less than controls $(\mathrm{p}<0.05)$.

\section{Discussion}

This study set out to examine the pulmonary expression of IL-18 under conditions characterized by Th1 and Th2 cytokine expression. The results demonstrate a constitutive expression of IL-18 within lung tissue from control mice and bronchial biopsies from normal human subjects. An

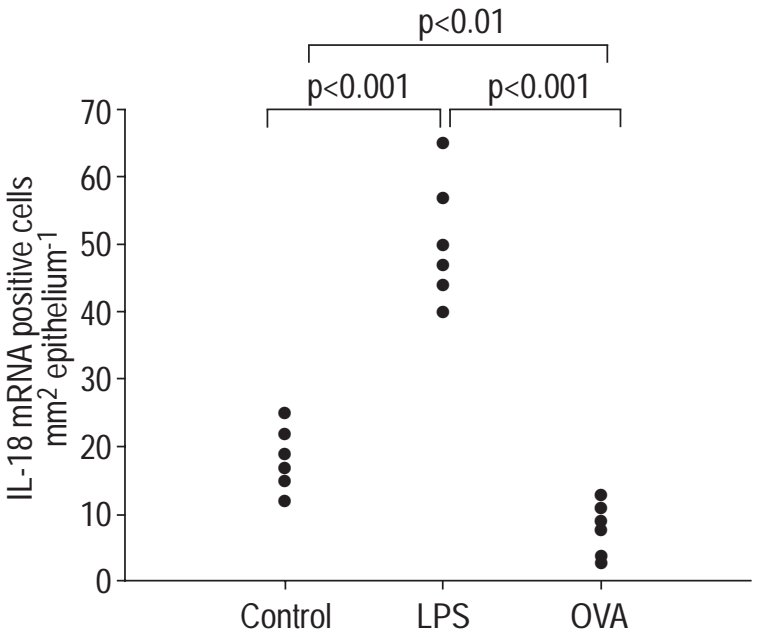

Fig. 3. - The number of interleukin (IL)-18 messenger ribonucleic acid (mRNA)-positive submucosal cells following treatment with lipopolysaccharide (LPS), ovalbumin (OVA) or in control animals. A greater number of IL-18 mRNA-positive cells were observed in LPS-treated animals compared to control $(\mathrm{p}<0.001)$ and OVA-challenged $(\mathrm{p}<0.001)$ mice. Significantly less IL-18 mRNA positive cells were observed within the lungs of OVA-challenged mice compared to controls $(\mathrm{p}<0.01)$. 

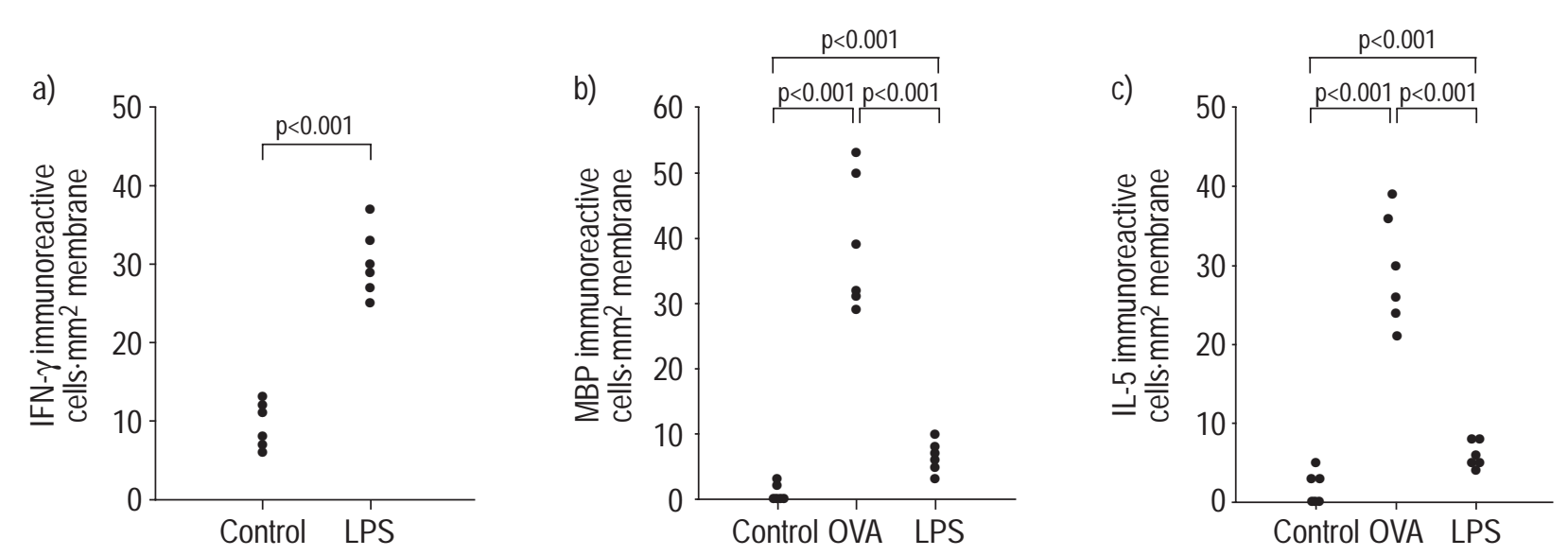

Fig. 4. - The number of interferon (IFN)- $\gamma$ (a), major basic protein (MBP) (b) and interleukin (IL)-5 (c) immunoreactive cells within the lungs of lipopolysaccharide (LPS)-treated, ovalbumin (OVA)-challenged or control mice. IFN- $\gamma$ immunoreactivity following LPS treatment was significantly higher than in control animals $(\mathrm{p}<0.001)$. The number of MBP and IL-5 immunoreactive cells were also increased after LPS challenge compared to control mice $(\mathrm{p}<0.001)$. MBP and IL-5 immunoreactivity was significantly higher following OVA-challenge than the LPS- or the control-treated mice $(\mathrm{p}<0.001)$.

increase in the number of IL-18 positive cells was observed within LPS-treated mice and sarcoidosis patients when compared to control groups, while OVA-challenged mice and asthmatic patients exhibited fewer IL-18 positive cells. These data also show that LPS-treated animals exhibited higher IFN- $\gamma$ immunoreactivity, while the number of IL-5 and MBP immunoreactive cells was increased both within animals that underwent OVA challenge as well as those which received LPS treatment.

To date, IL-18 has been identified mainly within activated macrophages, keratinocytes and within intestinal epithelial cells [1, 11-14]. Although IL-18 mRNA has been demonstrated in mouse lung homogenates following infection with Cryptococcus neoformans [25], the cellular expression of this cytokine within the lung has not yet been characterized. This study has shown that IL-18 is present within the airway wall and parenchyma and that the majority, both in murine and human tissue, was seen

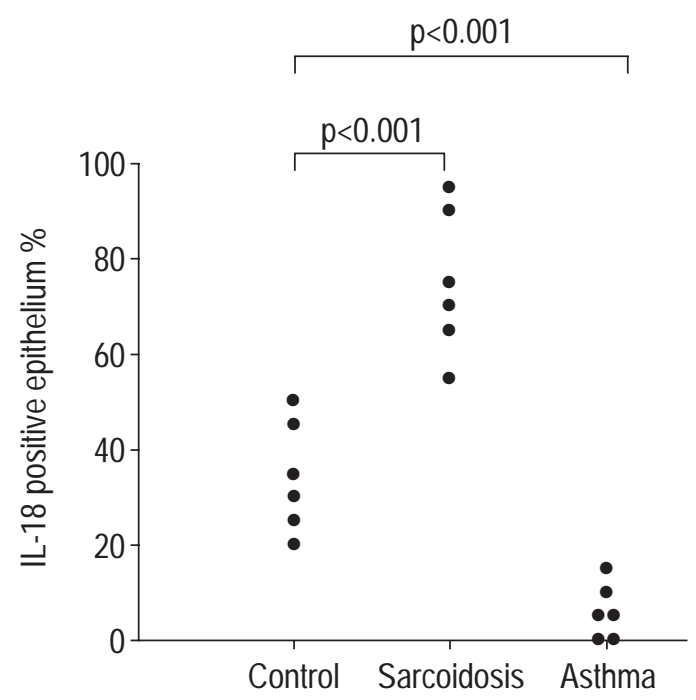

Fig. 5. - The percentage of interleukin (IL)-18 immunoreactivity within the epithelium of bronchial biopsies obtained from control subjects and patients with sarcoidosis or asthma. Significantly more IL-18 immunoreactivity was observed within the lungs of patients with sarcoidosis and significantly less within asthmatic tissue, compared to control subjects $(\mathrm{p}<0.001)$. within the epithelium. Many studies have now demonstrated the importance of the epithelium in immune defence, not merely as a protective barrier but also as an active cytokine and chemokine producer [26-28]. The results of this study identify IL-18 as a new member of this group of epithelial-derived mediators. While the significance of IL-18 expression by airway epithelium is not yet clear, it is possible that it acts on intraepithelial Tcells, many of which express the $\gamma \delta$ T-cell receptor (TCR) and are potent producers of IFN- $\gamma$ [29]. Alternatively, IL18 has been shown to induce IFN- $\gamma$ expression from bone marrow derived macrophages [3], which would suggest that it may also act on alveolar macrophages. The epithelium is the first point of contact between the respiratory tract and any inspired foreign agent. The fact that IL-18 is produced by this compartment suggests its role in the early stage of immune responses.

The constitutive pulmonary expression of IL-18 in control lung tissue is consistent with previous work demonstrating low levels of IL-18 mRNA in untreated epidermal cells [13] and may be explained by a recent report describing the regulation of the IL-18 gene by both a constitutively active as well as an inducible promoter [30]. Lung tissue examined $24 \mathrm{~h}$ following LPS challenge [17] exhibited a higher number of IFN- $\gamma$ immunoreactive and IL-18 mRNA positive cells within the airway wall and epithelium Correlational analysis indicated only a moderate association between these two, which failed to reach statistical significance. This could be explained by the small sample size $(n=6)$ or alternatively, a tighter relationship may exist between the protein for IL-18 and IFN- $\gamma$. One of the main functions of IL-18 is its ability to induce the production of IFN- $\gamma$ [2-7]. The elevated number of IL-18-positive cells within bronchial biopsies from sarcoidosis patients is consistent with previous work demonstrating increased expression of IFN- $\gamma$ within the same patient group [30]; however, it does not rule out the fact that IL-12 may also be involved. While the present study did not examine the expression of IL-4, significantly fewer IL-4 positive cells in bronchoalveolar lavage (BAL) fluid from patients with active sarcoidosis compared to control subjects has been demonstrated [31]. A negative correlation between IL-18 and IL-4 would be 
suggestive of a reciprocal inhibitory effect between these two cytokines, which may have previously been attributed to IFN- $\gamma$ and IL-12. Further study is required, however, in order to understand how IL-18 fits into the cytokine network.

As anticipated, OVA-challenged mice exhibited significantly more IL-5 and MBP immunoreactive inflammatory cells compared to the control group $6 \mathrm{~h}$ following challenge. The increase in these mediators is characteristic of the allergic response to antigen, and in agreement with these results, other studies have also demonstrated similar increases in lung eosinophilia, as early as $3 \mathrm{~h}$, after antigen challenge [32]. Alternatively, the early presence of eosinophils may be due to local maturation of precursor eosinophils within the tissue, a phenomenon currently under study.

More MBP immunoreactivity was observed within LPS-challenged compared to control mice. This finding was unexpected, however, as previous work has demonstrated that LPS administration is associated with eosinophil infiltration [29]. LPS activation of macrophages has been shown to result in the expression of eosinophil chemoattractants $[33,34]$ and depletion of these cells has been associated with inhibition of tissue eosinophilia [31]. Furthermore, IL-18 has been shown to induce the expression of GM-CSF, an important eosinophil-related cytokine, from these cells [8]. As such, it seems likely that macrophage activation, through LPS stimulation, may be at least partially responsibly for the observed eosinophil influx.

These results demonstrate that interleukin-18 is constitutively expressed in the airway epithelium and parenchyma of murine lung tissue and human bronchial biopsies and that its expression is increased under conditions characterized by T-helper1 cytokine expression such as lipopolysaccharide stimulation and pulmonary sarcoidosis. The results also suggest that the expression of interleukin18 is reduced within the lungs of mice and humans during T-helper2 cytokine-mediated conditions such as ovalbumin challenge and asthma. While RoBInson et al. [5] have shown that interleukin-18, unlike interleukin-12, does not directly drive the development of the T-helperl cytokine profile, epithelial expression of this cytokine indicates its importance during the early stages of host defence and amplification of T-helper1 cytokine expression.

\footnotetext{
Acknowledgements. The authors thank J. Gleich for the generous gift of mouse antibody recognizing MBP, B. Egan of Schering-Plough for the mouse antibody for IL-5 (TRFK-5), and C. Frag-
} iskatos for technical assistance.

\section{References}

1. Okamura $\mathrm{H}$, Tsutsul $\mathrm{H}$, Komatsu $\mathrm{T}$, et al. Cloning of a new cytokine that induces IFN- $\gamma$ production by $\mathrm{T}$ cells. Nature 1995; 378: 88-91.

2. Yoshimoto T, Okamura H, Tagawa YI, Iwakura Y, Nakanishi K. Interleukin-18 together with interleukin-12 inhibits $\operatorname{IgE}$ production by induction of interferon- $\gamma$ production from activated B cells. Proc Natl Acad Sci USA 1997; 94: 3948-3953.

3. Munder M, Mallo M, Eichmann K, Modolell M. Murine macrophages secrete interferon- $\gamma$ upon combined stimu- lation with IL-12 and IL-18: A novel pathway of autocrine macrophage activation. $J$ Exp Med 1998; 187(12): 2103-2108.

4. Kohno K, Kataoka J, Ohtsuki T, et al. IFN- $\gamma$-inducing factor (IGIF) is a costimulatory factor on the activation of Th1 but not Th2 cells and exerts its effect independently of IL-12. J Immunol 1997; 158: 1541-1550.

5. Robinson D, Shibuya K, Mui A, et al. IGIF does not drive Th1 development but synergizes with IL-12 for interferon- $\gamma$ production and activates IRAK and NFkB. Immunity 1997; 7: 571-581.

6. Barbulescu K, Becker C, Schlaak JF, Schmitt E, Meyer zum Buschenfelde KH, Neurath MF. IL-12 and IL-18 differentially regulate the transcriptional activity of the human IFN- $\gamma$ promoter in primary CD4+ T lymphocytes. J Immunol 1998; 160: 3642-3647.

7. Zang T, Kawakami K, Qureshi MH, Okamura H, Kurimoto M, Saito A. Interleukin-12 (IL-12) and IL-18 synergistically induce the fungicidal activity of murine peritoneal exudate cells against Cryptococcus neoformus through production of gamma interferon by natural killer cells. Infect Immun 1997; 65(9): 3594-3599.

8. Ushio S, Namba M, Okura T, et al. Cloning of the cDNA for human IFN- $\gamma$-inducing factor, expression in Escherichia coli, and studies on the biologic activities of the protein. J Immunol 1996; 156: 4274-4279.

9. Puren A, Fantuzzi G, Yong G, Su MSS, Dinarello C. Interleukin-18 (IFN- $\gamma$-inducing factor) induces IL-8 and IL-1, $\beta$ via TNF- $\alpha$ production from non-CD14+ human blood mononuclear cells. J Clin Invest 1998; 101: 711721.

10. Micallef MJ, Ohtsuki $\mathrm{T}$, Kohno $\mathrm{K}$, et al. Interferongamma-inducing factor enhances $\mathrm{T}$ helper 1 cytokine production by stimulated human $\mathrm{T}$ cells: synergism with interleukin-12 for interferon-gamma production. Eur $J$ Immunol 1996; 26(7): 1647-1651.

11. Matsui $\mathrm{K}$, Yoshimoto $\mathrm{T}$, Tsutsui $\mathrm{H}$, et al. Propionibacterium acnes treatment diminshes CD4+ NK1.1+ T cells but induces type I T cells in the liver by induction of IL-12 and IL-18 production from Kuffer cells. J Immunol 1997; 159: 97-106.

12. Rothe H, Jenkins NA, Copeland NG, Kolb H. Active stage of autoimmune diabetes is associated with the expression of a novel cytokine, IGIF, which is located near Idd2. J Clin Invest 1997; 99: 469-474.

13. Stoll S, Muller G, Kurimoto M, et al. Production of IL-18 (interferon-gamma-inducing factor) messenger RNA and functional protein by murine keratinocytes. $J$ Immunol 1997; 159: 298-302.

14. Takeuchi M, Nashizaki Y, Sano O, Ohna T, Ikeda M, Kurimoto M. Immunohistochemical and immuno-electromicroscopic detection of interferon-gamma-inducing factor ("interleukin 18") in mouse intestinal epithelial cells. Cell Tis Res 1997; 289: 499-503.

15. Ghayur T, Banerjee S, Hugunin M, et al. Caspase-1 processses IFN- $\gamma$-inducing factor and regulates LPS-induced IFN- $\gamma$ production. Nature 1997; 386: 619-623.

16. Ohkawara Y, Xue-Feng L, Stampfli MR, Marshall JS, Xing Z, Jordana M. Cytokine and eosinophil responses in the lung, peripheral blood and bone marrow compartments in a murine model of allergen-induced ariways inflammation. Am J Respir Cell Mol Biol 1997; 16: 510520.

17. Nill MR, Oberyszyn TM, Ross MS, Oberyszyn AS, Robertson FM. Temporal sequence of pulmonary cytokine gene expression in response to endotoxin in $\mathrm{C} 3 \mathrm{H} /$ 
$\mathrm{HeN}$ endotoxin-sensitive and $\mathrm{C} 3 \mathrm{H} / \mathrm{HeJ}$ endotoxin-resistant mice. J Leuco Biol 1994; 5: 563-574.

18. Dandurand RJ, Wang CG, Laberge S, Martin JG, Eidelman DH. In vitro bronchoconstriction in the Brown Norway rat. Am J Respir Crit Care Med 1994; 149: 1499_ 1505.

19. Crystal RG, Roberts WC, Hunninghake GW, Gadek JE, Fulmer JD, Line DR. Pulmonary sarcoidosis: a disease characterized and perpetuated by activated lung $\mathrm{T}$ lymphocytes. Ann Intern Med 1981; 94: 73-94.

20. Guidelines for the diagnosis and management of asthma. National Heart, Lung and Blood Institute. National Education Program. Expert Panel Report. J Allergy Clin Immunol 1991; 88: 425-534.

21. Workshop summary and guidelines: investigative use of bronchoscopy, lavage and bronchial biopsies in asthma and other airway diseases. J Allergy Clin Immunol 1991; 88: 808-814.

22. Durham SR, Ying S, Varney VA, et al. Cytokine mRNA for IL-3, IL-4, IL-5 and granulocyte/macrophage colony stimulating factor in the nasal mucosal after local allergen provocation: relationship to tissue eosinophilia. J Immunol 1992; 148: 2390-2394.

23. Giaid A, Michel RP, Stewart DJ, Sheppard M, Corrin B, Hamid Q. Expression of endothelin-1 in lungs of patients with crytogenic fibrosing alveolitis. Lancet 1993; 341: $1550-1554$.

24. Hamid Q, Azzawi M, Ying S, et al. Expression of mRNA for interleukin-5 in mucosal bronchial biopsies from asthma. J Clin Invest 1991; 87: 1541-1546.

25. Kawakami K, Qureshi MH, Zang T, Okamura H, Kurimoto M, Saito A. IL-18 protects mice against pulmonary and disseminated infection with Cryptococcus neoformans by inducing IFN-gamma production. $J$ Immunol 1997; 159: 5528-5534.
26. Matsukura S, Kokubu F, Noda H, Tokunaga J, Adachi M. Expression of IL-6, IL-8 and RANTES on human bronchial epithelial cells, NCI-H292, induced by influenza virus A. J Allergy Clin Immunol 1996; $98(6$ pt 1): 1080 1087.

27. Bochner M, Williams T, Schleimer RP. Production of the novel C-C chemokine MCP-4 by airway cells and comparison of its biological activity to other C-C chemokines. J Clin Invest 1997; 99: 926-936.

28. Lilly CM, Nakamura H, Kesselman H, et al. Expression of eotaxin by human lung epithelial cells: induction by cytokines and inhibition by glucocorticoids. J Clin Invest 1997; 99: 1767-1773.

29. Penido C, Castro-Faria-Neto H, Larangeira A, et al. The role of $\gamma \delta$-T lympocytes in lipopolysaccaride-induced eosinophil accumulation into the mouse pleural cavity. $J$ Immunol 1997; 159: 853-860.

30. Tone M, Thompson SAJ, Tone Y, Fairchild PJ, Waldman H. Regulation of IL-18 (IFN- $\gamma$ inducing factor) gene expression. J Immunol 1997; 159: 6156-6163.

31. Minshall EM, Tsicopoulos A, Yasruel Z, et al. Cytokine mRNA gene expression in active and nonactive pulmonary sarcoidosis. Eur Respir J 1997; 10: 2034-2039.

32. Rossi GA, Crimi E, Lantero S, et al. Late-phase asthmatic reaction to inhaled allergen is associated with early recruitment of eosinophils in the airways. Am Rev Respir Dis 1991; 144: 379-383.

33. Zhong WW, Burke PA, Hand AT, Walsh MJ, Hughes LA, Forse RA. Regulation of cytokine mRNA expression in lipopolysaccaride-stimulated human macrophages. Arch Surg 1993; 128: 158-163.

34. Oliveira SH, Faccioli LH, Cunha FQ, Ferreira SH. Participation of interleukin-5 and interleukin- 8 in the eosinophil migration induced by a large volume of saline. Intl Arch Aller Immunol 1996; 111: 244-252. 